\title{
Task 1, Milestone 1 - Alloy Selection
}

Carroll, L., McMurtrey, M., Wright, R., Messner, M., Jetter, R.

May 2018

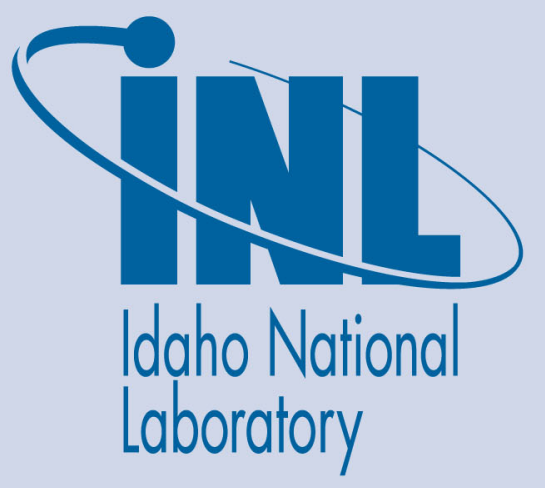

The INL is a U.S. Department of Energy National Laboratory operated by Battelle Energy Alliance 


\section{Task 1, Milestone 1 - Alloy Selection}

Carroll, L., McMurtrey, M., Wright, R., Messner, M., Jetter, R.

May 2018

Idaho National Laboratory Idaho Falls, Idaho 83415

http://www.inl.gov

Prepared for the U.S. Department of Energy

Office of Energy Efficiency and Renewable Energy

Under DOE Idaho Operations Office

Contract DE-AC07-05ID14517 
Research Performance Progress Report (RPPR) - DOE Solar Program

Project Title: $\quad$ Creep-fatigue Behavior and Damage Accumulation of a Candidate Structural Material for Concentrating Solar Power Solar Thermal Receiver

Project Period: $\quad$ 2/01/18 $-1 / 31 / 20$

Budget Period: $\quad$ 2/01/18 $-4 / 30 / 18$

Reporting Period: $\quad$ 2/01/18 - 4/30/18

Reporting Frequency: Quarterly

Submission Date: 5/15/18

Recipient:

Idaho National Laboratory

Address:

2525 Fremont Ave

Idaho Falls, ID 83402

Website (if available) www.inl.gov

Project Number: $\quad 33872$

Project Team: Idaho National Laboratory

Argonne National Laboratory

Principal Investigator: Michael McMurtrey, Materials Scientist

Phone: (208) 526-2327

Email: michael.mcmurtrey@inl.gov

Business Contact: $\quad$ Gabriel llevbare, Materials Science \& Engineering Manager Phone: 208-526-3735

Email: gabriel.ilevbare@inl.gov

HQ Tech Manager: $\quad$ Mark Lausten

HQ Project Officer: $\quad$ Christine Bing

GO Grant Specialist: $\quad$ GS name

GO Contracting Officer: CO name

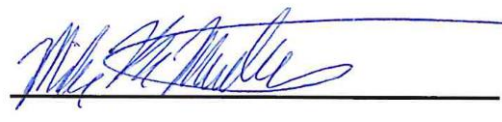

Signature

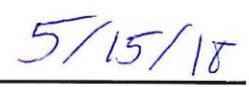

Date 
Creep-fatigue Behavior and Damage Accumulation of a Candidate Structural Material for Concentrating Solar Power Solar Thermal Receiver Michael McMurtrey

\section{Information from Statement of Project Objectives (SOPO)}

Project Objective: Creep-fatigue deformation is an important consideration for a thermal receiver of a gas phase (GP) Concentrating Solar Power (CSP) system due to the constant static stress or pressure, diurnal cycling, and elevated service temperatures required for efficient operation. An accurate description of the creepfatigue behavior, not available for five of the six the candidate materials, is important for assessment of preliminary designs. This project will provide a detailed analysis of the creep-fatigue behavior and damage accumulation of a candidate structural material for a CSP solar thermal receiver to address a critical knowledge barrier for receiver design in the GP pathway concept identified in the CSP Gen3 Demonstration Roadmap. This effort includes the development of rules for the design of solar receiver components against high temperature creep-fatigue and ratcheting failure modes. The ASME Code rules for high temperature nuclear components will form the basis of the method but adjustments will be made to reflect the generally shorter, diurnal operating cycles of thermal receivers and the relative consequences of failure, comparing nuclear to solar components.

\section{Work Planned for this Quarter:}

Task 1, Milestone 1 - Select an alloy for creep-fatigue testing and design modeling that is valuable and impactful to the Gen 3 effort. To ensure success, concurrence on the alloy selection of leading receiver developers, an ASME code expert, and DOE is important. This work will include a literature review of six candidate structural materials focusing on the amount of available creep and creep-fatigue data and material strength in the temperature regime of 700 to $850^{\circ} \mathrm{C}$ as well as other important alloy specific factors. Emails showing agreement with this report from lead receiver developers and an ASME code expert are attached to the end of this report.

Task 2, Milestone 1 - Assess, in consultation with an ASME Code expert, receiver design rules and their alignment with industry requirements including whether the design rules encompass anticipated component failure modes. Leading receiver developers, an ASME code expert, and DOE should concur on the selected design rules and anticipated failure modes. Emails showing agreement with this report from lead receiver developers and an ASME code expert are attached to the end of this report.

Task 2, Milestone 2 - This work will include the compilation and analysis of available creep data for the selected candidate alloy to determine if the existing data is sufficient and isochronous curves may be generated. If existing data is not available, recommendations for test conditions for creep testing will be defined and partial isochronous curves generated. If the existing data is sufficient, isochronous curves that cover expected component temperature and design life will be generated with the available test data. Concurrence from an ASME Code expert of the isochronous curves is included as part of this Task and contained at the end of this report.

\section{Plans for Next Quarter:}

Task 1, Milestone 2 - Plans for next quarter are to progress on-schedule to meet the Quarter 4 milestone. These plans include procuring Alloy $740 \mathrm{H}$ material and machining 
Creep-fatigue Behavior and Damage Accumulation of a Candidate Structural Material for Concentrating Solar Power Solar Thermal Receiver Michael McMurtrey

test specimens for creep and cyclic testing, and outlining an experimental test matrix. Depending on the timeline for material availability and cyclic machining, initial continuous-cycle fatigue tests may be underway this quarter. The experimental test program will be designed in accordance with the applicable ASTM test standards. The creep and creep-fatigue test matrices will be outlined to satisfy the ASME design curve requirements and an ASME Code expert will provide concurrence or recommended changes.

Task 2 - For design rules we will continue to evaluate existing approaches for a CSP design. Additionally, we will begin to develop a reference finite element model of a CSP receiver in the MOOSE framework. This model will be used to evaluate typical loading conditions to determine which transients must be represented in a trial component design. Eventually, this model will also be used to evaluate our proposed design rules.

Task 3 - Obtain DOE recommendations or concurrence for a shift in project scope for Task 3 to investigate the impact of a weld strength reduction factor and weldments, as well as other material forms (tube, sheet), on the creep-fatigue behavior of Alloy $740 \mathrm{H}$. This is specifically in relation to the creep-fatigue design rules and the potential impact of a detriment or benefit of weldments to the creep-fatigue resistance of Alloy $740 \mathrm{H}$. Initially, a thorough literature review will be conducted of similar nickel-base alloys and the potential influence of weldments, weld strength reduction factor, and material product forms on the resulting creep-fatigue behavior. If Task 3 will be shifted to a preliminary investigation of the influence of weldments and product forms on the creepfatigue behavior of Alloy $740 \mathrm{H}$, material will be obtained for this study.

\section{Narrative Report and Update:}

Project Results and Discussion: The metric for Task 1, Milestone 1 is the selection of a single nickel-base alloy that is impactful to the Gen3 effort to investigate as part of the project. The high temperatures of an in-service receiver ultimately require that the structural material be capable of not only withstanding creep deformation, but also diurnal high temperature cycling $[1,2]$. For the CSP technology to meet cost goals, the receiver must meet a lifetime requirement of 30 years or 10,000 cycles [1,2]. Candidate materials for a thermal receiver have been identified [3] and include commercial nickelbase alloys, Alloy 625, INCONEL ${ }^{\circledR}$ alloy $740 \mathrm{H}$ (herein referred to as Alloy $740 \mathrm{H}$ ), Alloy 230, and Haynes ${ }^{\circledR} 282$ alloy (herein referred to as Alloy 282). After project initiation, further discussion indicated that Alloy 617 and Alloy $X$ should also be considered. The temperature range of interest was identified as 700 to $850{ }^{\circ} \mathrm{C}$ to enable both gas and salt CSP technologies with an outlet temperature of $750{ }^{\circ} \mathrm{C}$ and the associated higher wall temperatures.

Creep-fatigue and creep property data for an alloy are critical as they are the basis of the creep-fatigue interaction diagram, or D-diagram, constructed using a linear damage summation of the individual creep and fatigue terms, such as in the case of the ASME Boiler and Pressure Vessel Code Section III, Division 5 (Subsection HB, Subpart $B$ for Class A components at elevated temperatures) [4]. While these rules may be more conservative than necessary for a CSP application [2, 5], a linear summation damage assessment is typically utilized for creep-fatigue [6] and an accurate assessment of a CSP thermal design will require a valid D-diagram. 
Creep-fatigue Behavior and Damage Accumulation of a Candidate Structural Material for Concentrating Solar Power Solar Thermal Receiver Michael McMurtrey

As part of the alloy selection, the availability of creep-fatigue and creep property data, alloy strength, and heat treatment schedule were considered. The goal being to select an alloy for creep-fatigue investigation, in agreement with DOE program managers, that will ultimately be impactful to the Gen3 effort and receiver developers and manufactures.

While the physical and mechanical properties such as the creep and low cycle fatigue are often readily available, the creep-fatigue properties, for most of the candidate alloys, are not. The main exception is for Alloy 617 for which there is a published creep-fatigue interaction diagram [7] based upon data from four sources [811] in the temperature range from 800 to $1000^{\circ} \mathrm{C}$ [7]. Additionally, a Larson-Miller creep equation developed for Alloy 617 from 348 rupture specimens from multiple heats and product forms and tested at temperatures from 593 to $1093{ }^{\circ} \mathrm{C}$ exists. There are also additional sources of continuous-cycle and creep-fatigue data from tests at temperatures from 700 to $850{ }^{\circ} \mathrm{C}$ [12-17]. Only limited creep-fatigue tests at specific conditions in the lower temperature regime would be necessary to assess solar-specific design rules.

In the case of Alloy 230, continuous cycle fatigue [15, 18-21] and creep-fatigue [2122] data is available from which to begin constructing a creep-fatigue interaction diagram, however, additional creep-fatigue tests at test conditions differing from those in the literature would be necessary. A published creep-fatigue diagram for Alloy 230 includes limited data from a single source tested at a single temperature, $850^{\circ} \mathrm{C}$ [16]. Some creep tests would be necessary to verify the existing $1 \%$ creep and creep rupture life regression model [23], applicable for times up to $175,000 \mathrm{~h}$ and at temperatures from 527 to $927^{\circ} \mathrm{C}$.

In contrast, there is not an available creep-fatigue interaction diagram or a creep regression equation for Alloy 282. Some creep data is published [24-28], however, the available Larson-Miller equation is specifically for sheet material [27] and much of the data [24-27] is for the material with a double step ageing treatment. A single step ageing treatment has been investigated; findings suggest that the creep strength, at temperatures between 700 and $800^{\circ} \mathrm{C}$, was similar, however, no conclusions were drawn on the creep ductility [28]. For a creep-fatigue interaction diagram to be developed as part of this project, only creep data from material with a single step ageing treatment would be utilized, thereby reducing the amount of available creep data. Furthermore, there is no creep-fatigue data available in the open literature for Alloy 282, but a limited amount of lower temperature continuous-cycle fatigue data does exist [27, 29-32]. Clearly, more extensive creep-fatigue testing and creep testing of single step aged material would be necessary to develop applicable creep-fatigue design rules and an associated creep-fatigue interaction diagram.

For Alloy $740 \mathrm{H}$, with the exception of limited data at $700{ }^{\circ} \mathrm{C}$ [12], there is also no creep-fatigue data, nor an associated creep-fatigue interaction diagram. A vast amount of creep testing was completed at temperatures up to $850^{\circ} \mathrm{C}[28,33]$ and creep rupture equations are available [28,34]. These sources additionally contain a sufficient set of complete creep curves to construct isochronous curves at least at $700^{\circ} \mathrm{C}$. Furthermore, there has been an analysis of the creep-fatigue design rules for Alloy $740 \mathrm{H}$ [12]. Zhang and Takahashi [12] have published creep-fatigue properties and the assessment of three life prediction methods, time fraction, ductility exhaustion, and modified ductility 
exhaustion. Minimal creep testing would likely be necessary for validation of the existing creep models, yet a substantial amount of creep-fatigue testing would be required.

Unlike Alloys $740 \mathrm{H}$ and 282 , there is creep-fatigue data available for Alloy $\mathrm{X}$ at temperatures above $800{ }^{\circ} \mathrm{C}[22,35-36]$. There is also a Larson-Miller regression equation developed from 276 data points with test temperatures ranging from 600 to $1000{ }^{\circ} \mathrm{C}$ [37]. Data for Alloy XR (modified alloy X composition, particularly in $\mathrm{Si}$, Ti, and Mn content) was utilized to develop the equation. There are other sources of creep data for Alloy X [35, 38-39], but it is not clear whether they were included in developing the regression equation. The current assessment of creep and creep-fatigue data available from published articles and material suppliers for candidate alloys is depicted in Figure 1.

\begin{tabular}{|l|l|l|l|}
\hline Alloy & Creep & $\begin{array}{c}\text { Creep-Fatigue } \\
700 \text { to } 800{ }^{\circ} \mathrm{C}\end{array}$ & $\begin{array}{c}\text { Creep-Fatigue to } \\
800 \text { to } 1000{ }^{\circ} \mathrm{C}\end{array}$ \\
\hline Alloy 617 & & & \\
\hline Alloy 230 & & & \\
\hline Alloy 282 & & & \\
\hline Alloy $740 \mathrm{H}$ & & \\
\hline Alloy $\mathrm{X}$ & & & \\
\hline
\end{tabular}

Figure 1. Qualitative summary of the amount of creep and creep-fatigue property data available for Alloys $617,230,282,740 \mathrm{H}$, and X. Red indicates limited or no data, yellow means some data available, and green that considerable data exists.

While there currently is only limited cyclic data, Alloys $740 \mathrm{H}$ and 282 are substantially stronger than Alloys $230,617,625$, and X. The former two alloys have significantly higher 100,000 h rupture creep strengths in comparison to Alloys 617, X, and 230 [40]. A Larson-Miller plot is shown in Figure 2 to compare Alloy $740 \mathrm{H}$ and Alloy 617 and Table 1 provides the estimated stresses for creep rupture in 100,000 h at 750, 800 , and $850^{\circ} \mathrm{C}$. Additionally, Alloy $740 \mathrm{H}$ has a high allowable stress value at temperatures lower than approximately $800^{\circ} \mathrm{C}$ in ASME Section I, Code Case 2702 [41] in comparison to Alloy 617, Alloy X, and 230 , as shown in Figure $3(\mathrm{a})$. After $625^{\circ} \mathrm{C}$, the stress allowables decrease rapidly for Alloy $740 \mathrm{H}$ until they merge with the other candidate alloys. The Section I max use temperature for Alloy $740 \mathrm{H}$ is $800^{\circ} \mathrm{C}$. It is possible that the Larson-Miller correlation used to determine the allowables was not carefully calibrated above the max use temperature and so the Section I allowables may not be the best metric for evaluating high temperature strength near or above $800{ }^{\circ} \mathrm{C}$. 
Alloy $740 \mathrm{H}$ also exhibits longer continuous cycle and creep-fatigue cycle lifetimes at 700 ${ }^{\circ} \mathrm{C}$ than Alloy 617 based on the data from [12], as reproduced in the plot in Figure 4. The increased fatigue and creep-fatigue resistance is particularly evident at the lower strain ranges, 0.5 and $0.7 \%$ total strain.

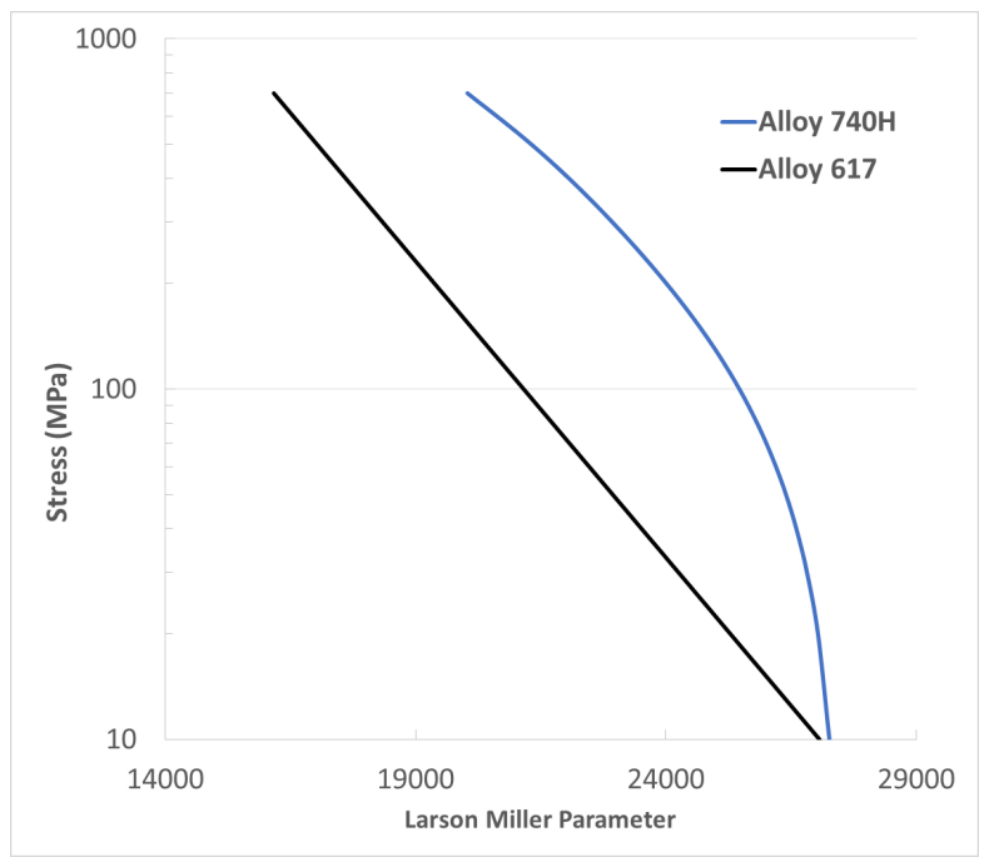

Figure 2. Stress (MPa) v. the Larson-Miller Parameter plot for the Alloy $740 \mathrm{H}$ [41] and Alloy 617 [42]. The value of the $\mathrm{C}$ is 19.472 for Alloy $740 \mathrm{H}$ and is 16.730 for Alloy 617 , temperature is in Kelvin, and time is in hours.

Table 1: The approximate 100,000 and $10,000 \mathrm{~h}$ rupture strength for Alloy 617 and $740 \mathrm{H}$ estimated from the Larson-Miller plot in Figure 2.

\begin{tabular}{|c|c|c|c|c|}
\hline & \multicolumn{2}{|c|}{$100,000 \mathrm{~h}$ Rupture Strength } & \multicolumn{2}{c|}{$10,000 \mathrm{~h}$ Rupture Strength } \\
\cline { 2 - 5 } & Alloy 740H & Alloy 617 & Alloy 740H & Alloy 617 \\
\hline Temperature $\left({ }^{\circ} \mathrm{C}\right.$ ) & Stress (MPa) & Stress (MPa) & Stress (MPa) & Stress (MPa) \\
\hline 750 & $\sim 125$ & $\sim 65$ & $\sim 200$ & $\sim 100$ \\
800 & $\sim 60$ & $\sim 45$ & $\sim 120$ & $\sim 65$ \\
825 & $\sim 30$ & $\sim 35$ & $\sim 85$ & $\sim 55$ \\
\hline
\end{tabular}




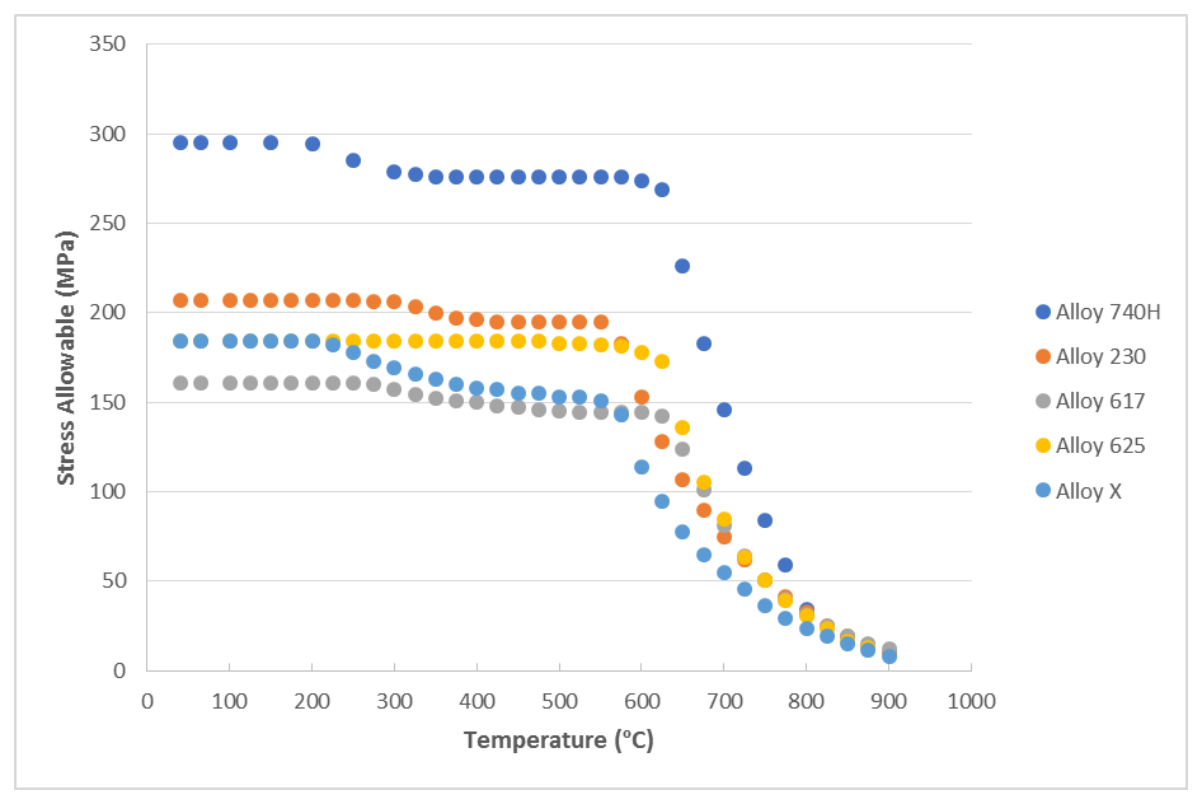

(a)

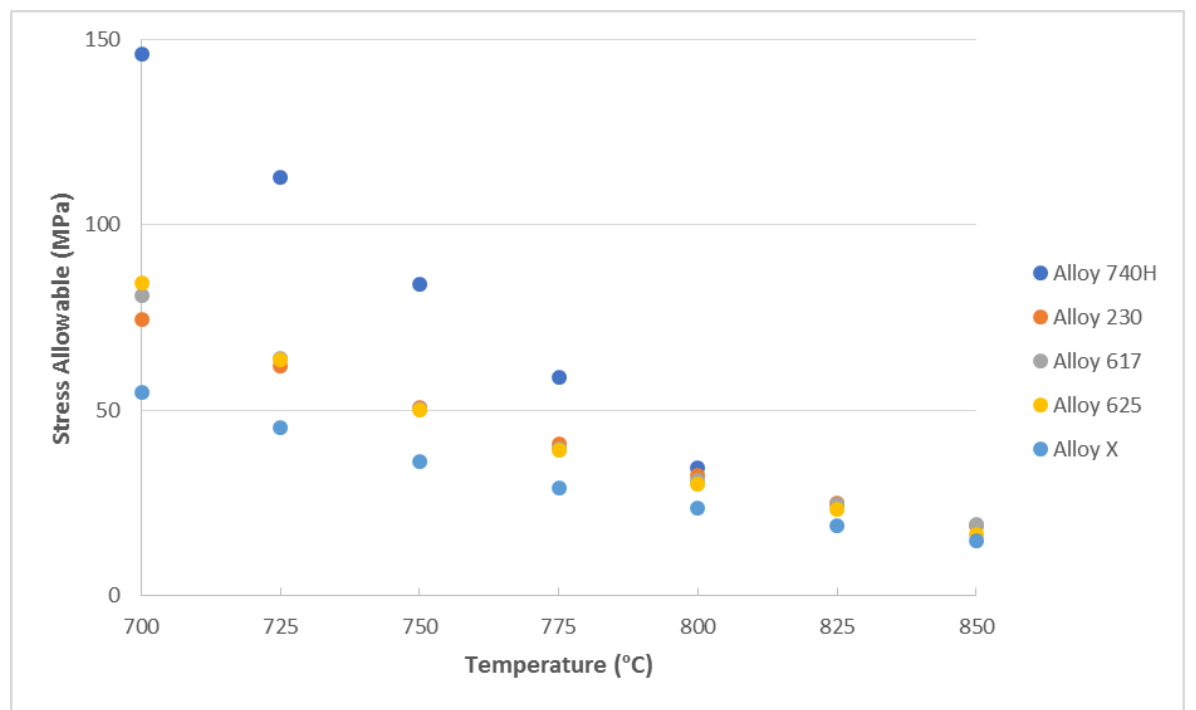

(b)

Figure 3. ASME Code Section I Stress allowables for seamless tubing for Alloys $740 \mathrm{H}$ [41], 230, 617, 625, and X [43] including the full temperature range (a) and for temperatures from 700 to $850^{\circ} \mathrm{C}(\mathrm{b})$. 


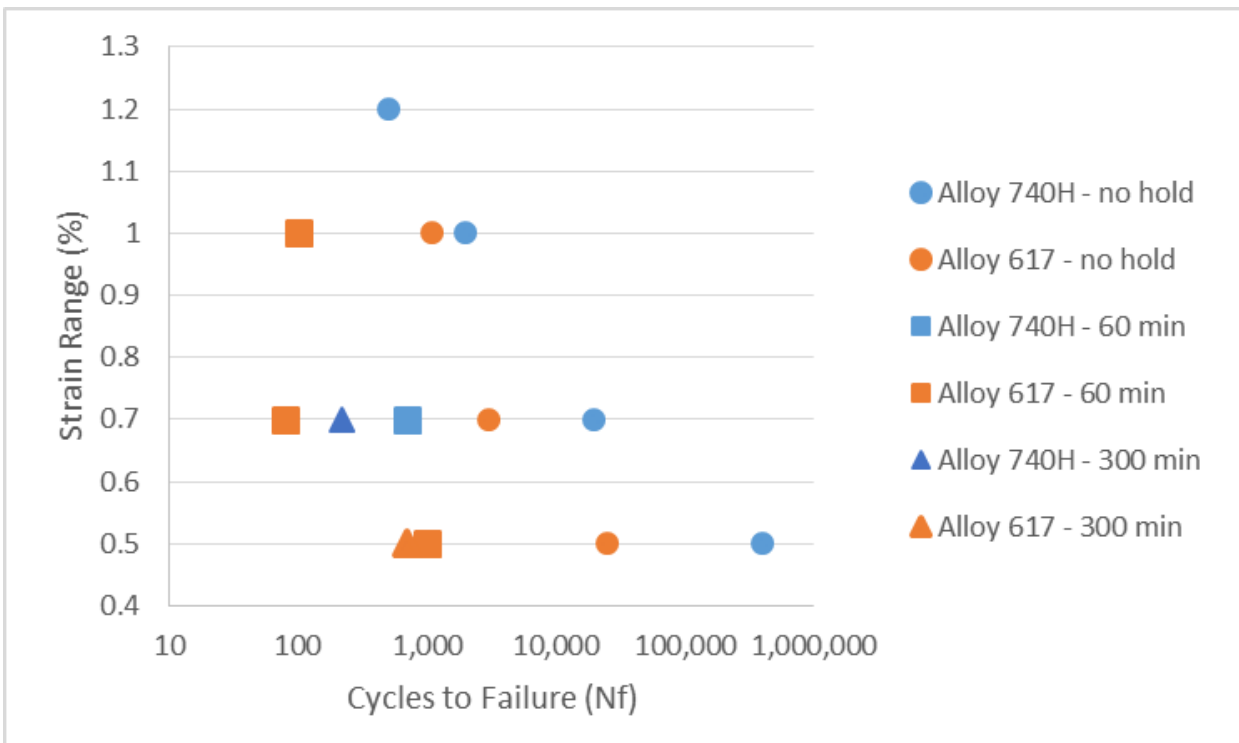

Figure 4. Estimates of the data from Zhang and Takahashi [12] reproduced on a plot of total strain range (\%) $v$. approximate cycles to failure $\left(\mathrm{N}_{\mathrm{f}}\right)$ for fully-reversed fatigue and creep-fatigue of Alloy $740 \mathrm{H}$ and Ally 617 at $700{ }^{\circ} \mathrm{C}$.

The compositions of Alloys $740 \mathrm{H}$ and 282 are similar, with approximately $50 \mathrm{wt} \% \mathrm{Ni}$ and at least $20 \mathrm{wt} \% \mathrm{Cr}$, while also containing $\gamma$ forming elements Co and Mo and $\gamma^{\prime}$ forming elements Al and Ti. The lower high temperature strength of Alloys 617, 230, and $\mathrm{X}$ is due to the fact that they are predominately solid solution strengthened, whereas Alloys $740 \mathrm{H}$ and 282 are also strengthened by $\gamma^{\prime}$ precipitates. The microstructural stability with regard to these strengthening precipitates, for which an initial investigation has been carried out [44], will also need to be considered, particularly at temperatures above $800^{\circ} \mathrm{C}$.

The considerable amount of research focused on Alloys $740 \mathrm{H}$ and 282 has been motivated by advanced-ultrasupercritical (A-USC) power plant applications and is part of a large DOE Fossil Energy program [40]. For A-USC applications, materials would need to withstand steam temperatures of up to $760^{\circ} \mathrm{C}$ placing them in a similar temperature regime to CSP thermal receivers. It has been recognized that nickel-base alloys are necessary to provide adequate strength at temperature, thus not surprisingly, a similar set of alloys to those being considered for CSP thermal receivers were assessed. As part of this assessment, the creep properties of weldments have been investigated and the weld strength reduction factor is likely near 1 for Alloy 282, whereas it 0.7 for Alloy $740 \mathrm{H}$ [28]. However, Alloy $740 \mathrm{H}$ has a single step ageing treatment and has recently been accepted into the ASME Boiler and Pressure Vessel Code Case 2702, which includes tensile properties, allowable stresses, and physical properties [44]. As part of the A-USC program, research on Alloy $740 \mathrm{H}$ has focused on the creep properties [28, 45], fabricability and weldability [40], influence of deformation and aging on creep rupture properties [28] and the tensile properties [28]. Further research will be necessary on the propensity of Alloy $740 \mathrm{H}$ to form extraneous phases, particularly the eta phase [45], at temperatures of $800^{\circ} \mathrm{C}$ and above. The research 
Creep-fatigue Behavior and Damage Accumulation of a Candidate Structural Material for Concentrating Solar Power Solar Thermal Receiver Michael McMurtrey

conducted as part of the A-USC program has furthered the knowledge base of both Alloy $740 \mathrm{H}$ and Alloy 282 and provides a starting point for future CSP efforts.

The metric for Milestone 1 of Task 1 is that the alloy selected for creep-fatigue testing and for the design model is valuable and impactful to the Gen 3 effort and the measure of success is based on concurrence of leading receiver developers, an ASME code expert and DOE on the selection of the alloy for further testing. The conclusion of Task 1, Milestone 1 is, despite the absence of available creep-fatigue data, a longerterm view suggests that higher stress allowables below $800^{\circ} \mathrm{C}$ and the higher creep resistance in addition to the single step ageing treatment of Alloy $740 \mathrm{H}$ will likely be viewed as most favorable to solar receiver designers. It is noted that as service temperatures increase beyond $800{ }^{\circ} \mathrm{C}$ for gas-phase receivers, a different candidate alloy may be preferred. For the current project, a large database of creep properties for Alloy $740 \mathrm{H}$ and the analyzed regression equation will serve as the foundation for calculating the creep damage of the creep-fatigue tests and enable eventual placement on the D-diagram. Additionally, the extensive amount of Alloy $740 \mathrm{H}$ research conducted as part of the A-USC program will provide a baseline. For these reasons, this project will primarily focus its creep-fatigue investigation on Alloy $740 \mathrm{H}$.

Task 2, Milestone 1 is an assessment of the design rules encompassing anticipated component failure modes. A description of the evaluation of the design rules and the future direction of this project with regard to developing these rules is described in the following paragraphs.

The design rules developed in the course of this project must guard against the expected failure modes in concentrating solar power receivers. Receivers are subject to two general types of load in ordinary high temperature service: pressure induced by the heat transfer medium and thermal stresses induced by the incident solar radiation. A complete receiver design must additionally account for ordinary structural loading, primarily dead load of components located above the receiver and wind load, as well as extraordinary structural loads, primarily earthquake loading. These structural considerations, however, are beyond the scope of the project, which will concentrate on standard elevated temperature service.

The final design rules should encompass all potential receiver types, but the design studies performed in this project will focus on tubular gas and liquid receivers, which are bundles of tubes connected with pipe manifolds at the ends. The expected design pressure induced by the heat transfer medium, compressed air or $\mathrm{SCO}_{2}$ for gas receivers and water/steam or liquid salt for liquid receivers, varies greatly by type. For gas receivers, pressures may be as high as $15-25 \mathrm{MPa}$ for $\mathrm{sCO}_{2}[5,46]$ and, for salt systems, pressures may be as low as $1 \mathrm{MPa}$ [46]. The other two working fluids induce pressures somewhere in between these extremes.

The receiver will be subject to both axial and circumferential thermal stresses as the solar radiation is concentrated on one side of the tubes and is non-uniformly distributed axially along the receiver. Previous design studies show the axial and circumferential thermal stresses are approximately equal $[1,2]$ and that the axial stress distribution tends to resemble a bending stress state [47]. Additionally, the thermal stresses are cyclic. During the day small variations in the incident solar radiation, e.g. a cloud occluding the sun, induce oscillations in the thermal stresses. Daily the receiver 
Creep-fatigue Behavior and Damage Accumulation of a Candidate Structural Material for Concentrating Solar Power Solar Thermal Receiver Michael McMurtrey

undergoes variation when the sun rises and sets. The annual variation of insolation produces yearly changes in the thermal loading [1]. These short and long-term variations cause thermal creep-fatigue damage in the receivers. Typical design lifetimes cited are 30 years or approximately 10,000 day-night cycles [1, 2].

Most of the previous design studies reference the work of Berman et al. [48], a Sandia National Laboratory report from 1979 establishing draft design guidelines for concentrating solar power facilities. In modern terminology, the draft guidelines are an amalgamation of provisions from several divisions of the ASME Boiler and Pressure Vessel Code [43], roughly Section III, Division 5 (Rules for Construction of Nuclear Facility Components, High Temperature Reactors), Section VIII, Division 1 (Rules for Construction of Pressure Vessels, Design-by-Rule), and Section VIII, Division 2 (Rules for Construction of Pressure Vessels, Design-by-Analysis). Though specifics vary from section to section of the Code, most high temperature design provisions guard against failure through the following mechanisms:

1. Time-independent plastic instability

2. Time-dependent creep rupture

3. Creep-fatigue damage

4. Time-dependent, cyclic excessive deformation (ratcheting)

5. Time-independent buckling

6. Time-dependent buckling.

All of which are potentially relevant to high temperature solar power receivers.

The ASME Code typically lumps the first two mechanisms together into the "primary load" design used to size the vessel section thickness. Most previous design studies apply the Section VIII rules, arguing the nuclear Code rules are too restrictive. While $740 \mathrm{H}$ has not yet been approved for Section VIII use, the required design data have been established and incorporated into Section III via the Section I Code Case [41]. Since the Section VIII rules are widely applied and understood, they will be adopted for this project.

This project will focus on the ASME linear damage summation approach to creepfatigue design, though it will also examine the ductility exhaustion approach [49] in a simple design study. The former approach was adopted by the Sandia draft standard [48] and has been used in most subsequent design studies. To implement the linear damage summation the required design information includes a creep-rupture correlation, fatigue curves, and a D-diagram. The Section I Code Case [41] developed a rupture correlation and the latter two requirements will be developed through Task 1 of this project.

One previous study [47] asserts that creep damage will be negligible in solar receivers, reducing the problem to pure fatigue design. This study asserted that the subdaily solar variation would cause short term, elastic, high-cycle fatigue damage in the receiver and that the daily cycles would not contribute a large amount of creep-fatigue damage. However, a detailed inelastic analysis of a typical receiver design [1] demonstrated the opposite - the sub-daily cycles do contribute creep relaxation damage and hence creep-fatigue damage, at least partly due to fast stress relaxation times at elevated temperatures. At least a priori then, the design rules must encompass creep-fatigue damage. Finally, the work of Zhang and Takahashi [12] examines creepfatigue damage in $740 \mathrm{H}$ and concludes that the linear damage summation does not 
Creep-fatigue Behavior and Damage Accumulation of a Candidate Structural Material for Concentrating Solar Power Solar Thermal Receiver Michael McMurtrey

work well for $740 \mathrm{H}$ when $700{ }^{\circ} \mathrm{C}$ experimental data is assessed. However, the authors of that study used a D-diagram with intercepts $(0,1)$ and $(1,0)$ (i.e. no creep-fatigue interaction), which is unlikely to actually apply to $740 \mathrm{H}$. The creep-fatigue tests conducted during the project will establish an experimentally-based damage interaction for $740 \mathrm{H}$ and then the linear damage summation approach can then subsequently be properly evaluated.

There are two additional issues related to creep-fatigue raised based upon previous design studies. The first, going back to the Sandia draft standard [48], is that, by volume, the tubes mostly experience compressive thermal stresses. For some materials compressive holds are much less damaging than tensile holds and so the nuclear approach (which generally considers compression and tension equally when computing creep damage) may be overly-conservative. The experimental program will assess the effect of compression versus tension holds for $740 \mathrm{H}$ and the final design rules will make a recommendation based on these results. The second issue was raised in [47], citing a personal communication with experimentalists at various DOE laboratories. Fatigue studies on tube materials apparently show much shorter fatigue lives than standard ASTM fatigue studies using solid specimens machined from plate or bar stock. The authors [47] associate this issue with the crack-growth stage of fatigue and differences in the crack driving force between a thin tube cross-section and a thick solid specimen. Initially in this project, a literature review will assess this question in order to provide a recommendation for progressing with the testing of tubular for $740 \mathrm{H}$.

The original draft standard [48] design guidelines explicitly did not require a check on ratcheting strain accumulation. Instead, they make two, somewhat contradictory, statements as to why this potential service-failure mechanism was neglected: a) ratcheting is not significant for solar receivers as the components can be inspected more frequently than nuclear reactors (i.e. during the diurnal off-cycle period) and b) other design provisions tacitly guard against ratcheting. While solar receivers can be frequently inspected, this does not mean a design should not consider ratcheting strain accumulation as excess accumulated deformation can cause the service failure of a component prior to achieving the full design life. Due to frequent inspections this may not be a safety issue, but it is certainly an economic issue, particularly if excess deformation requires the repair or replacement of the receiver. The design rules developed in this study will therefore guard against excessive ratcheting, with the goal of the project being to develop simple rules for ratcheting, compared to the Section III, Division 5 elastic analysis approach. One reasonable starting point might be Code Case $\mathrm{N}-47$ providing ratcheting strain accumulation rules using a simplified elastic perfectlyplastic analysis. The required design data for these rules are a set of isochronous stress-strain curves, which are addressed in the next section.

Buckling, particularly time-dependent buckling under thermal bending stress, may also be an important potential failure mode [47]. A detailed study of buckling in tubes at high temperatures is beyond the scope of this project's experimental program. However, the design study will consider existing Section VIII and Section III rules and make some recommendation on which provisions may be applicable or if further experimental and design rule development studies are required. 
Creep-fatigue Behavior and Damage Accumulation of a Candidate Structural Material for Concentrating Solar Power Solar Thermal Receiver Michael McMurtrey

Further, several heat transfer media proposed for use in CSP facilities are corrosive. Traditionally, the ASME Code neglects explicit consideration of corrosion. Detailed corrosion studies are also beyond the scope of the project experimental study.

Overall then, this project will focus on developing rules to guard against creepfatigue failure and ratcheting strain accumulation, focusing on Alloy $740 \mathrm{H}$ and on tubular solar receiver designs. The starting point for these design rules will be the ASME high temperature nuclear reactor Code rules or applicable, simplified Code Cases. The design margin in these rules may be altered to better suit the frequent inspections and lower consequences of failure for solar systems. Existing Code rules for primary load design and buckling will be referenced in the final design guidelines to guard against the remaining potential failure mechanisms.

The metric for Task 2, Milestone 2 is that isochronous curves are produced for use by industry designers to initiate designing and also the determination of whether existing data is sufficient to generate isochronous curves. Two types of creep data are required to underlie the ratcheting and creep-fatigue design rules proposed for development in the previous section: creep rupture lives and isochronous stress strain curves.

Conventionally, creep-rupture design data is generated by extrapolating the results of higher stress, shorter term tests to lower stress, longer life design conditions. The fossil energy program that developed $740 \mathrm{H}$ generated an extensive collection of creeprupture data on the alloy at several different temperatures and for several different heats and product forms $[28,50]$. They proposed a correlation to the Larson Miller parameter

$$
\log \sigma_{r} \sim T\left[\log t_{r}+C\right]
$$

where $\sigma_{r}$ is the rupture stress, $T$ the absolute temperature, $t_{r}$ the rupture time, and $C$ a constant with $\mathrm{C}$ approximately equal to 20 . This Larson-Miller correlation forms the basis of the ASME Code Case 2702 [41] time-dependent allowable stresses for $740 \mathrm{H}$ incorporated into Section II of the Code [51]. This correlation has been vetted by the relevant ASME Code committees and so will likely be adopted for use in this project. However, if required, the raw data used to create the Larson-Miller relation is available in [28] and this database could be used to calibrate a new rupture life correlation. Either way extensive creep testing to generate rupture data, as part of the current program, is not necessary. Several creep tests may be run to verify that the available rupture equation is representative of the Alloy $740 \mathrm{H}$ material to be tested as part of this program.

Two sources for full creep curves were identified: the fossil energy program report [28] and a paper by Zhang and Takahashi [52]. These works focus on temperatures between 700 and $800{ }^{\circ} \mathrm{C}$, dictated by temperatures in ultra-supercritical coal plants. Between these two sources there are 12 creep tests at various stresses and temperatures, mostly at 700 and $750^{\circ} \mathrm{C}$, whereas there is only a single curve at $800^{\circ} \mathrm{C}$. Additionally, Zhang and Takahashi [52] have reported a series of tensile tests at $700{ }^{\circ} \mathrm{C}$ and several strain rates. This existing data is sufficient to assemble isochronous stressstrain curves for $740 \mathrm{H}$ at $700{ }^{\circ} \mathrm{C}$ and with the addition of a tensile test at $750{ }^{\circ} \mathrm{C}$, the available creep data will be also be sufficient to assemble isochronous curves at that temperature as well. The available creep data at $800{ }^{\circ} \mathrm{C}$ is insufficient to create isochronous curves. Therefore, recommendations include that: 
1. The experimental program conduct tensile testing at 700 (for confirmation of the existing literature data), 750 , and $800{ }^{\circ} \mathrm{C}$ according to the ASTM E21 standard [53].

2. At least two confirmatory, short-term creep tests be performed at both 700 and $750^{\circ} \mathrm{C}$ to ensure the material procured for this project is comparable to the material used in [28] and [52]. The ASME Code Case asserts that there is very little data scatter for different batches and product forms, however, creep tests are notoriously prone to experimental scatter.

3. Utilizing available data, ratcheting design provisions may be set at $750^{\circ} \mathrm{C}$ with limited additional testing, performed as part of this project. Additional long term creep testing (approximately 10,000 hour test time) as well as short term testing (less than 10,000 hours) is recommended for higher temperatures of up to $850^{\circ} \mathrm{C}$ to enable ratcheting design provisions to be extended to $850^{\circ} \mathrm{C}$. DOE concurrence will be obtained to identify the recommended temperatures for ratcheting design provisions.

Note that recommendation \#3 does not apply to creep-fatigue rules, which could be developed at higher temperatures without long-term creep testing by relying on the Larson-Miller correlation.

As noted, there is sufficient data in the literature to construct isochronous curves for $740 \mathrm{H}$ at $700{ }^{\circ} \mathrm{C}$. Isochronous curves give the material flow stress as a function of time and strain and can be viewed as a way to summarize creep test data for design purposes. Commonly, isochronous stress-strain curves are drawn by first fitting a model for the material strain as a function of time and stress and then inverting the equation to get strain/strain isochrons.

We propose a model for $740 \mathrm{H}$ of the form

$$
\varepsilon=\varepsilon_{e}+\varepsilon_{p}+\varepsilon_{c}
$$

where $\varepsilon$ is the total strain, $\varepsilon_{\varepsilon}$ the elastic strain, $\varepsilon_{p}$ the plastic strain, and $\varepsilon_{c}$ the creep strain. The elastic strain is

$$
\varepsilon_{e}=\frac{\sigma}{E}
$$

with $\sigma$ the stress and $E$ the material Young's modulus. The plastic strain uses a Ramberg-Osgood model [54]

$$
\varepsilon_{p}=\left\{\begin{array}{cc}
0 & \sigma \leq \sigma_{p l} \\
\left(\frac{\sigma-\sigma_{p l}}{k_{1}}\right)^{1 / k_{2}} & \sigma>\sigma_{p l}
\end{array}\right.
$$

where $\sigma_{p l}$ is the proportional limit and $k_{1}$ and $k_{2}$ are material constants. Finally, the creep strain follows a Norton-Bailey [55] model

$$
\varepsilon_{c r}=A \sigma^{n} t^{m}
$$

where $A, n$, and $m$ are all material parameters. Table 2 lists the values of the parameters at $700^{\circ} \mathrm{C}$, calibrated to the literature data. 
Table 2: Parameters used for isochronous curve model.

\begin{tabular}{lll}
\hline Parameter & Units & Value \\
\hline$E$ & GPa & 164.3 \\
$\sigma_{p l}$ & $\mathrm{MPa}$ & 419 \\
$k_{1}$ & $\mathrm{MPa}$ & 241 \\
$k_{2}$ & - & 0.289 \\
$A$ & $\mathrm{MPa}{ }^{-n} \mathrm{hr}^{-\mathrm{m} \%}$ & $8.59 \times 10^{-75}$ \\
$n$ & - & 25.6 \\
$m$ & - & 2.70 \\
\hline
\end{tabular}

Figure 5 compares the hot tensile curve from the literature at $700^{\circ} \mathrm{C}$ to the model prediction. Similarly, Figure 6 compares the model predictions for creep strain to the experimental counterparts. Both models fit the data reasonably well, implying the final isochronous curves will reasonably characterize the material at this temperature. Finally, Figure 7 plots the values of the isochronous curve implied by the model. These curves will form the basis for the design rules for bounding ratcheting strain accumulation.

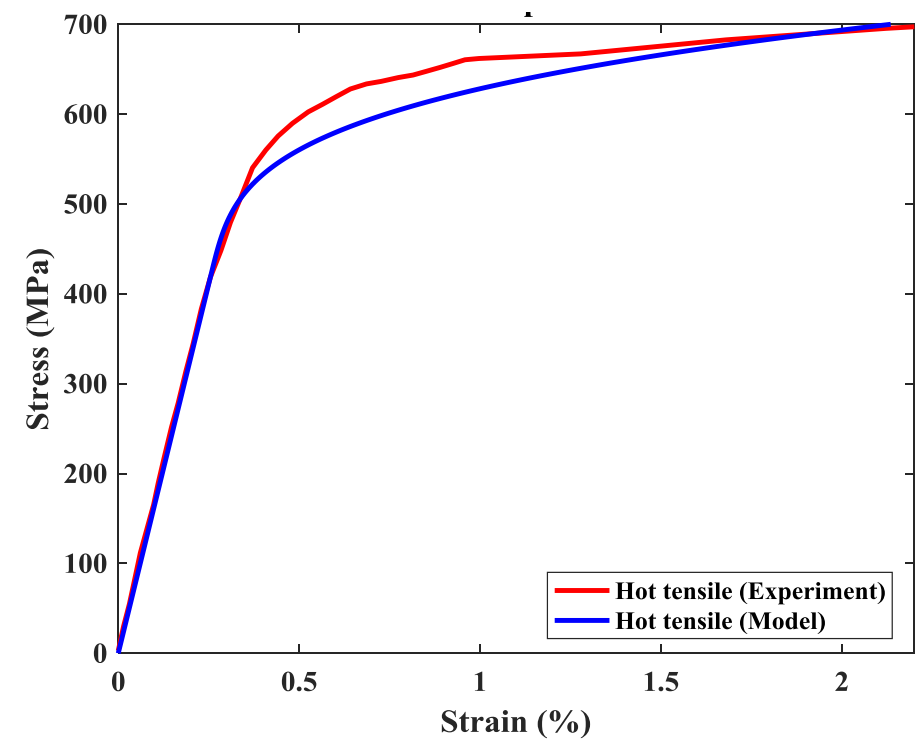

Figure 5: Plot comparing the proposed tensile model to the experimental data from [52]. 


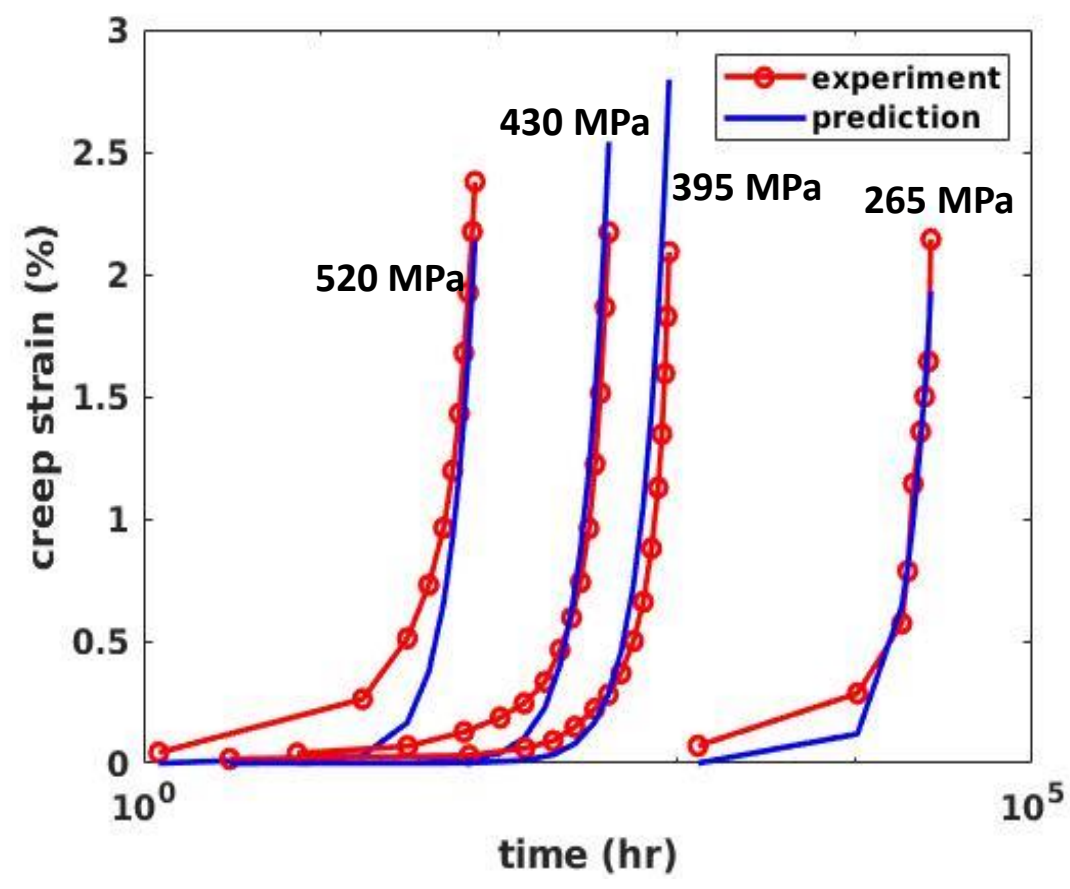

Figure 6: Plot comparing the proposed model for creep strain to the available experimental data from [28] and [52].

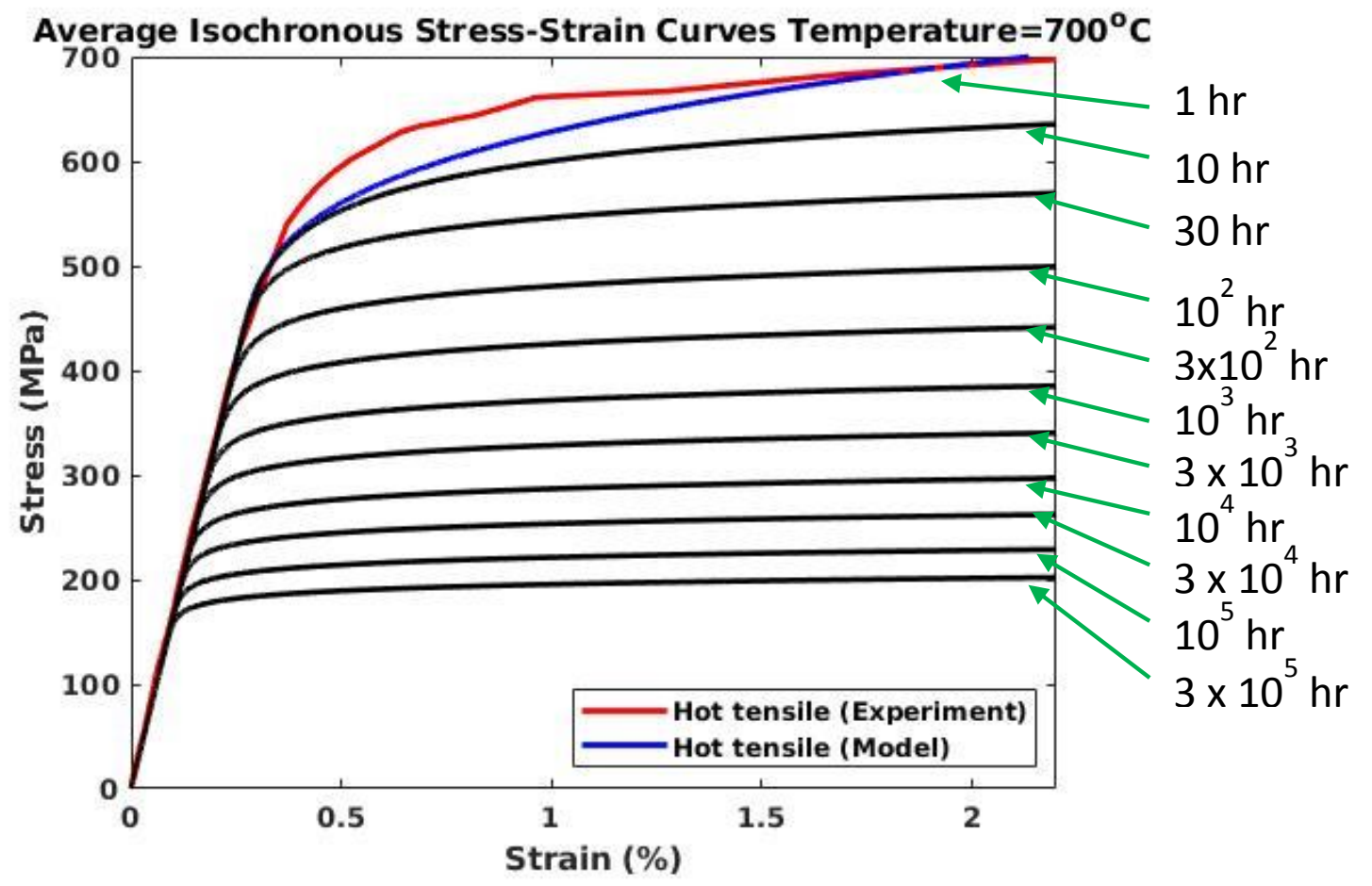

Figure 7: Isochronous stress-strain curves for $740 \mathrm{H}$ at $700^{\circ} \mathrm{C}$. Experimental hot tensile curve from [52]. 
Creep-fatigue Behavior and Damage Accumulation of a Candidate Structural Material for Concentrating Solar Power Solar Thermal Receiver Michael McMurtrey

Update on the State of the Art:

The significance of this project is in delivering (1) a description of the creep-fatigue behavior of a candidate alloy at conditions applicable for a solar thermal receiver and (2) a set of proposed design rules that provide a more accurate assessment of creepfatigue damage in solar thermal receivers. This will include a preliminary recommendation of a creep-fatigue interaction diagram (D-diagram) based upon an assessment of the materials' creep-fatigue response in the temperature range of 700 to $850^{\circ} \mathrm{C}$.

Aligning the experimental testing program to approximate the expected failure modes for the solar thermal receiver in-service is important. As mentioned in the above section addressing the analysis of the design rules encompassing anticipated components failure modes, a consideration of the position of the hold time during creepfatigue cycling should be undertaken. To do this published literature data on another nickel-base alloy, Alloy 617, was considered. While Alloy 617 does not contain as much of the gamma prime strengthening phase as Alloy $740 \mathrm{H}$, it provides a preliminary indication of the creep-fatigue behavior related to tensile or compressive dwell sensitivity and is described in the following paragraph.

Previous, work by Rao and co-workers [56] tested both compression-only and tensile-only hold times at an intermediate strain range at $950^{\circ} \mathrm{C}$ in an impure helium environment. They found that the two compression-only hold time tests ( 1 and $10 \mathrm{~min}$ hold times) had longer cycles to failure than the tensile-only hold tests [56]. At the same conditions of $0.6 \%$ total strain at $950{ }^{\circ} \mathrm{C}$, a cycle with both a 5 minute tension and $5 \mathrm{~min}$ compression hold time resulted in a greater number of cycles to failure than either the tension-only or compression-only hold time tests. Carroll et al. [57] also conducted a couple of alternate waveform tests at $950^{\circ} \mathrm{C}$, one of which had a compression-only hold time and two of which had a symmetric (tension and compression) hold times. The key difference in these tests to those of Rao and co-workers was the lower total strain range, $0.3 \%$ total strain. The compression-only hold time tests exhibited a similar number of cycles to failure as the tension-only hold time tests [57]. Whereas, the symmetric hold time specimen had a greatly reduced number of cycles to failure relative to either of the tension-only or compression-only hold time. For Alloy 617 at this strain range, variations in the number of cycles to failure were directly related to the inelastic strain range of the hysteresis loops during cycling [57].

It is noted that the experimental testing program on Alloy $740 \mathrm{H}$ will first need to determine whether tensile or compressive hold times are more damaging to the creepfatigue resistance. Several initial tests at multiple strain ranges and the two test temperatures will be conducted to determine the dwell sensitivity for Alloy $740 \mathrm{H}$.

Similarly, additional consideration of the weld strength reduction factor may be necessary. The alloy selected for creep-fatigue testing and analysis of the creep-fatigue design rules, Alloy $740 \mathrm{H}$, does have a weld strength reduction factor of 0.7 [28]. This is an area for which a literature review of similar nickel-base alloys will be conducted next quarter and the influence on the resulting creep-fatigue behavior assessed. Based on these learnings, consideration may be given to shifting Task 3 , currently focused on an assessment of the environment on the creep-fatigue behavior, to a preliminary investigation of the influence of weldments on the creep-fatigue behavior of Alloy $740 \mathrm{H}$. 
Creep-fatigue Behavior and Damage Accumulation of a Candidate Structural Material for Concentrating

[1] D.K. Fork, J. Fitch, S. Ziaei, R.I. Jetter, J. Solar Ener. Engin. 134 (2012).

[2] J. Ortega, S. Khivsara, J. Christian, C. Ho, P. Dutta, Applied Thermal Engin. 109 (2016) 979-987.

[3] M. Mehos, C. Turchi et al., NREL/TP-5500-67464 (2017).

[4] ASME, 2015, ASME Boiler and Pressure Vessel Code, Section III, Division 5, "Rules for Construction of Nuclear Facility Components, High Temperature Reactors," ASME, New York.

[5] T.W. Neises, M.J. Wagner, A.K. Gray, Proc. ASME 2014 8th Inter. Conf. on Energy Sustainability ES2014 June 30-July 2, 2014, Boston, Massachusetts, USA.

[6] X. Chen, M.A. Sokolov, et al., J. Nuclear Materials 432 (2013) 94-101.

[7] J.K. Wright et al., Proc. of the ASME 2016 Press. Vessels Piping Con. PVP201663704 July 17-21, 2016, Vancouver, British Columbia, Canada.

[8] L.J. Carroll, C. Cabet, M.C. Carroll, R.N. Wright, Inter. J. Fatigue 47 (2013) 115-125.

[9] L. Carroll, INL/EXT-15-35132 R1, August 2015.

[10] T. Totemeier, H. Tian, Mater. Sci. Engin. A 468-470 (2007) 81-87.

[11] P.G. Pritchard, L. Carroll, T. Hassan, Trans. of the Amer. Nuclear Soc., 109 (2013) 562-565.

[12] S. Zhang, Y. Takahashi, Adv. Mater. Tech. Fossil Power Plants Proc., Albufeira, Algarve, Portugal (2016).

[13] K. Kubushiro, H. Yoshizawa, T. Itou, H. Nakagawa, Proc. of CREEP8, July 22-26, 2007, San Antonio, Texas.

[14] J.P. Strizak et al, Oak Ridge National Laboratory, ORNL/TM-8130 (April 1982).

[15] R. Seeley et al., Fatigue in Modern Nickel-Base Alloys for Gas Turbine

Applications, Life Assessment of Hot Section Gas Turbine Components, Cambridge University Press, UK (2000) 61-82.

[16] X. Chen et al. J. Nuc. Mater. 444 (2014) 393-403.

[17] http://www.specialmetals.com/assets/smc/documents/alloys/inconel/inconel-alloy617.pdf

[18] P.R. Barrett et al., Inter. J. Solids Struc. 88-89 (2016) 146-164.

[19] B.R. Antoun, K.J. Connelly, S.H. Goods, G.B, Sartor, Mechanics of Time-

Dependent Materials Springer International Publishing 2(10) (2015) 81-87.

[20] S.K. Srivastava, D.L. Klarstrom, ASME Paper 90-GT-80, Inter. Gas Turbine Conf., Brussels, Belgium, June 11-14, 1990.

[21] L.J. Carroll, W.R. Lloyd, J.A. Simpson, R.N. Wright, Mater. High Temp. 27(4) 313323.

[22] S.Y. Lee et al., Mater. Sci. Engin. A 504 (2009) 64-72.

[23] D.R. Eno, G.A. Young, T.L. Sham, ASME 2008 Press. Vessels Piping Conf. 6 Chicago, Illinois, USA, July 27-31, 2008.

[24] C.J. Boehlert, S.C. Longanbach, Mater. Sci. Engin. A 528 (2011) 4888-4898.

[25] X. Song, L. Tang, Z. Chen, R. Zhou, J. Mater. Sci. 52 (2017) 4587-4598.

[26] P.J. Maziasz, et al., Adv. Mater. Tech. Fossil Power Plants Proc. $8^{\text {th }}$ Inter. Conf. Oct. 11-14, 2016, Albufcira, Algarve, Portugal.

[27] http://haynesintl.com/docs/default-source/pdfs/new-alloy-brochures/hightemperature-alloys/brochures/282-brochure.pdf?sfvrsn=20 
Creep-fatigue Behavior and Damage Accumulation of a Candidate Structural Material for Concentrating Solar Power Solar Thermal Receiver Michael McMurtrey

[28] R. Purgert et al. Boiler Materials for Ultra Supercritical Coal Power Plants Final Technical Report for DOE Award DE-FG26-01NT41175., Dec. 2015.

[29] R. Brommesson, M. Ekh, Mater. High Temp. 31 (2014) 121-130.

[30] M. Hornqvist, C. Joseph, C. Persson, J. Weidow, H. Lai, MATEC Web of Conf. 14, 16002 (2014).

[31] L.M. Pike, ASME Turbo Expo, GT2007-28267, ASME Publication, New York, NY, 2007.

[32] J. He, R. Sandstrom, S. Notargiacomo, J. Mater. Engin. Performance 26 (2017) 2257-2263.

[33] J.P. Shingledecker, Metallurgical Effects of Long-Term Stress Rupture in a New

Nickel-Base Alloy, Doctoral Dissertation, U. Tennessee, Knoxville, May, 2012.

[34] http://www.specialmetals.com/assets/smc/documents/alloys/inconel/inconel-alloy740-h.pdf

[35] Y. Muto, H. Nakajima, M. Eto, Nucl. Engin. Design 144 (1993) 305-315.

[36] H. Tsuji, T. Kondo, T., J. Nucl. Mater. 150 (1987) 259-265.

[37] S.N. Yin, Exper. Mech. Nano Biotech. Key Engin. Mater. 326-328 Trans Tech Publications (2006) 1105-1108.

[38] Haynes International http://haynesintl.com/docs/default-source/pdfs/new-alloybrochures/high-temperature-alloys/brochures/x-brochure.pdf?sfvrsn=8

[39] M.K. Booker, Oak Ridge National Laboratory, ORNL-5479 (February 1979).

[40] J. Shingledecker, R. Purgert, P. Rawls, Adv. Mater. Tech. Fossil Power Plants Proc. October 22-25, 2013, Waikoloa, Hawaii.

[41] ASME International, ASME Boiler and Pressure Vessel Code, Code Case 2702-3 Ni-25Cr-20Co Material Section I, 2017.

[42] ASME International, ASME Boiler and Pressure Vessel Code, Draft Section III Div 5 Alloy 617 Code Case, In Progress.

[43] ASME Boiler and Pressure Vessel Code, American Society of Mechanical Engineers, 2017.

[44] J.P. Shingledecker, G.M. Pharr, Metall. Mater. Trans. A 43 (2012) 1902-1910.

[45] J.P. Shingledecker, N.D. Evans, G.M. Pharr, Mater. Sci. Engin. A 578 (2013) 277286.

[46] C.K. Ho, B.D. Iverson, Renewable and Sustainable Energy Reviews, 29 (2014) 835-846.

[47] E.F. Radke et al., Proceed. ASME Symposium on Elevated Temperature Application of Materials for Fossil, Nuclear, and Petrochemical Industries (2014) 116.

[48] I. Berman et al., An Interim Structural Design Standard for Solar Energy Applications, Sandia National Laboratories, 1979.

[49] R. Hales, Fatigue of Engin. Mater. Structures, 6(2) (1983) 121-135.

[50] J.P. Shingledecker, G.M. Pharr, J. Mater. Engin. Performance 22(2) (2013) 454462.

[51] ASME Boiler and Pressure Vessel Code, Section II: Materials. American Society of Mechanical Engineers, 2017.

[52] S. Zhang, Y. Takahashi Advances in Materials Technology for Fossil Power Plants: Proc. Seventh Inter. Conf., Waikoloa, Hawaii, USA, 2013. 
[53] ASTM E21-17: Standard Test Methods for Elevated Temperature Tension Tests of Metallic Materials, ASTM International, 2017.

[54] W. Ramberg, W.R. Osgood, Description of stress-strain curves by three parameters, National Advisory Committee for Aeronautics, 1943.

[55] F.H. Norton, The Creep of Steels at High Temperatures, McGraw-Hill, New York, NY, 1929.

[56] K.B.S. Rao, H.P. Meurer, H. Schuster, Mater. Sci. Engin. A 104 (1988) 37-51.

[57] M.C. Carroll, L.C. Carroll, Metall. Mater. Trans. A 44 (2013). 
The following correspondence are included as assurance of completion of Task 1 , Milestone 1 and Task 2 Milestones 1 and 2, in accordance with the project SOPO.

$5 / 14 / 2018$

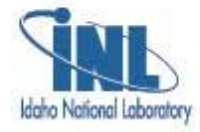

Idaho Nationa Laboratory Mail - Gen3 CSP lab program

Mchurtrey, Michael D <michael.mcmurtrey@inl.govs

\section{Gen3 CSP lab program}

David Wait <David. Waitiosolarreserve.com>

To: "McMurtrey, Michael D" <michael. mcmurtrey@inl.gov>

Mon, May 14,2018 at $11: 52 \mathrm{AM}$

Michael,

SolarReserve has reviewed and discussed the selection of alloy materials suitable for receiver tubes selected for further creep-fatigue testing and design modeling. We have also discussed the types of design analyses that are currently being used to assess the influence of cyclic thermal strain on lifetime. We agree that for future CSP applications the selection of Alloy $740 \mathrm{H}$ is a mean ingful choice for further investigation of creep fatigue interaction.

Best,

David Wait

SOLARRESERVE

Solar Energy with htegrated Storage

520 Broadwey, 6th Floor | Santa Monica, CA 90401

Direct: +1.310 .315 .2245$

SolarReserve.com | davidwait (aSolarReserve.com

Facebook | Twitter | Linkedin | YouTube

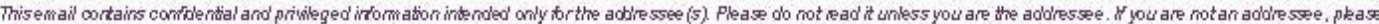
rotify the semder by reply entail and destroy the orizinal in essage and al copies.

From: McMurtrey, Michael D<michael.mcmurtrey@inl.gov>

Sent: Monday, May 14, 2018 10:37 AM

To: David Wait <David. Wait@ solarreserve.com>

[Quoted text hidden]

[Quoted text hidden] 


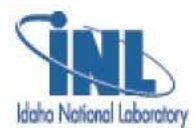

McMurtrey, Michael D <michael.mcmurtrey@inl.gov>

\section{RPPR1 Q1 201833872 draft.pdf}

Jim Nash <nash@braytonenergy.com>

Mon, May 14, 2018 at 12:46 PM

To: "McMurtrey, Michael D" <michael.mcmurtrey@inl.gov>

Cc: Shaun Sullivan <sullivan@braytonenergy.com>

H Mike,

Thank you for the opportunity to review plans within the attached RPPR for Q1 2018. The planned work is indeed relevant to our needs with respect to designing CSP receivers. Task 1/Milestone 1 and Task2/Milestone 1 are relevant as they will provide data we need to design high temperature, high pressure flow distribution components. I am also very interested in design data that may be derived from Task 3 . Our designs are striving to minimize pressure boundary thickness as a means to reducing through-wall thermo-mechanical stress in response to extreme heat fluxes attendant with CSP. To this end, creep characteristics for sheet and foil forms of alloys are of interest. And to the extent that we employ welding and brazing in processing CSP absorber panels, and welding to join panels into receiver assemblies and for system integration, how weld strength affects design will be important to us as well.

Thanks and best wishes,

$\operatorname{Jim}$

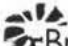

TBrayton Energy

Jim Nash

Engineering Director

Brayton Energy LLC

$6036010450 \times 203$ office

6034983754 mobile

7 RPPR1 Q1 201833872 draft.pdf

$732 \mathrm{~K}$ 


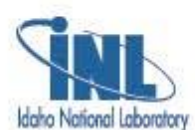

Mchurtrey, Michael D <michael.mcmurtrey@inl.gov>

\section{CSP report review}

1 message

bjetter@sbcglobal.net<bjetter@sbcglobal.net>

Tue, May 15,2018 at 2:14 PM

To: "McMurtrey, Michael D" <michael.mcmurtrey@inl.gov>, "Messner, Mark Christian" <messner@anl.gov>

Mike and Mark,

I have reviewed the quarterly Progress Report for the Concentrating Solar Power (CSP) project and am in general agreement with the conclusions reached. I would also offer the following general observations:

1. The higher strength of Alloy 704 up to $800^{\circ} \mathrm{C}$, as reflected in the current allowable stre ss values, also has a direct benefit on the magnitude of thermal stress levels in systems where the wall thickness is driven by pressure considerations. The resultant lower required wall thickness will both reduce the temperature difference through the wall and the maximum outer wall temperature.

2. There is a current Section VIII, Div 2 code case, CC-2843, which closely follows the requirements in Section III, Div 5 , Part HB, Subpart B. They are currently endeav oring to expand the materials covered beyond the original five base materials in Div 5 and there might be some benefits to coordination with that activity

3. Some years ago, there was a problem with premature failures of Section I Heat Recovery Steam Generators (HRSGs) due to frequent, severe thermal cycling. One of the approaches they took to resolve the problem was configuration control of stress risers in critical components. Similar configuration control of critical tube to header joints in the CSP may be worth consideration in addition to design evaluation methodology.

Robert (Bob) Jetter

Member, BPV-III, SC-D, SG-HTR, SG-ETD, WG-HTLR, WG-HTGR, WG-ASC and WG-CFNC 